\title{
The Application of Grey Model to the Prediction of Extreme Sea States Induced by Typhoon
}

\author{
Liang Pang \\ Ocean University of China \\ Qingdao, China \\ pang@ouc.edu.cn
}

\author{
Yu-Long Li \\ Chinese Navy Institute of Engineering Design \& Research \\ Qingdao, China \\ woliyulong@gmail.com
}

\begin{abstract}
The sea state of South China is influenced by typhoon obviously. It is important to carry out the long-term prediction of typhoon wind, wave height and wave period for the coastal and offshore engineering. In this paper the measured wind and wave data during typhoon processes from 1964-1989 are used to predict the extreme sea states by using Grey Markov Chain Model. The calculated results show the reasonableness of the proposed method.
\end{abstract}

key words - Typhoon, Extreme sea states, Long term prediction, Grey Markov Chain Model.

\section{INTRODUCTION}

Catastrophes induced by typhoon always bring the severe damages in coastal and offshore regions of China Sea. The study of typhoon induced sea environment conditions is the important problem in the designing of coastal and offshore structures. The routine way is to carry out statistic analysis using measured or hindcast data to reflect the wave characteristics $^{[1]}$. In the engineering field, long-term prediction of extreme sea conditions is normally based on series of wind and wave parameters, which are fitted to some probability distributions, such as Extreme Value I (Gumbel), Extreme Value II ,Extreme Value III (Weibull) and some joint probability distributions ${ }^{[2]-[8]}$. The accuracy of the method depends on the data quality of sea states. If the measured data is not enough, the hindcast data will be needed.

In this paper the Grey Markov Chain Model (CMGM) will be proposed for prediction of typhoon induced sea conditions.

\section{METHODOLOGY}

Grey Model (GM) is firstly proposed by Deng, which is the effective approach for dealing with the variable series with strongly random characteristic ${ }^{[9]}$. The most common grey forecasting model is $\operatorname{GM}(1,1)$. First order differential equation is adopted to match the data generated by the Accumulation Generating Operations (AGO). The model can be established as following.

Let the original data series $X$ be $X^{(0)}=\left(x^{(0)}(1), x^{(0)}(2), x^{(0)}(3), \ldots, x^{(0)}(n)\right)$.
Then generate the one-time AGO series $\mathrm{X}(1)$ by $x^{(1)}(k)=\sum_{i=1}^{k} x^{(0)}(i) . \mathrm{X}(1)$ can be modeled by a first order differential equation as:

$$
\frac{d x}{d t}+a u=u
$$

In Eq.1, the parameter a is called the developing coefficient and $\mathrm{u}$ is named grey input. The values of $a$ and $u$ can be estimated by the least-squares error method.

After substituting values of $a$ and $u$ into Eq.1, the solution of Eq. 1 can be further defined. The initial condition is set as $X^{(1)}(1)$, the 1-step ahead forecasted value (time response function) can be written as:

$$
\widehat{x}^{(1)}(t)=\left[x^{(0)}(1)-\frac{u}{a}\right] e^{-a t}+\frac{u}{a}(t=1,2, \ldots, n)
$$

Finally, the predicted value can be estimated as:

$$
\begin{aligned}
& \widehat{x}^{(0)}(1)=x^{(0)}(1), \\
& \hat{x}^{(0)}(t+1)=\widehat{x}^{(1)}(t+1)-\widehat{x}^{(1)}(t), \\
& \hat{y}(t)=\widehat{x}^{(0)}(t+1)
\end{aligned}
$$

In the above-mentioned algorithm of $\operatorname{GM}(1,1)$, the initial condition is set as. $X^{(1)}(1)$ This way will pay more importance on the farthest datum of modeling data, so the use of the latest datum may not be enough, which may create some errors in the prediction. Therefore, $\operatorname{GM}(1,1)$ may not have enough ability to predict the fluctuate variance. This paper, hence, proposes setting the initial condition as $X^{(1)}(n)$ to fully catch the latest tendency which is based on the principle that new information should be used fully. Thus, the solution of Eq.1 can be written as: 


$$
\hat{x}^{(1)}(t)=\left[x^{(1)}(n)-\frac{u}{a}\right] e^{-a(t-n)}+\frac{u}{a}(t=1,2, \cdots, n)
$$

And the predicted value can be still estimated as:

$$
\begin{aligned}
& \widehat{x}^{(0)}(1)=x^{(0)}(1), \\
& \widehat{x}^{(0)}(t+1)=\widehat{x}^{(1)}(t+1)-\widehat{x}^{(1)}(t), \\
& \widehat{y}(t)=\widehat{x}^{(0)}(t+1)
\end{aligned}
$$

GM is suitable for the prediction of short data series with upward trend. For the strongly fluctuating variables such as extreme sea environment conditions, the predicted results will show the obvious error. So in this study, Grey Markov Chain Model (GMCM) is used for dealing with the prediction error and increasing the model accuracy. In GMCM the residual error of prediction value (see Eq.4) is divided into different states, and the state transition probability from state $i$ to state $j$ after k steps is obtained by Eq.5.

$$
\begin{aligned}
& \Delta_{k}(k)=\frac{x^{(0)}(k)-\widehat{x}^{(0)}(k)}{x^{(0)}(k)}, k=1,2, \ldots, n \\
& P_{i j}(k)=\frac{M_{i j}(k)}{M_{i}}, i=1,2, \ldots, n
\end{aligned}
$$

where $\operatorname{Mij}(k)$ is the number of state transition from state $i$ to state $j$ after k steps and $M i$ is the total number of $i$ state. Finally, the s-state m-step state transition matrix is defined as:

$$
P(k)=\left[\begin{array}{cccc}
p_{11}(k) & p_{12}(k) & \cdots & p_{1 n}(k) \\
p_{21}(k) & p_{22}(k) & \cdots & p_{2 n}(k) \\
\vdots & \vdots & \vdots & \vdots \\
p_{n 1}(k) & p_{n 1}(k) & \cdots & p n n(k)
\end{array}\right]
$$

Because of the uncertainty of last state, it usually eliminates the last $\mathrm{k}$ data when establishing $\mathrm{k}$ step state transition probability matrix. And because there are uncertainties in the boundary of the state, we can make sure the future transition state $E i$ of the system by a lot of pilot calculation. And interval of prediction value is $[E 1 i, E 2 i]$. The prediction value can be obtained as:

$$
\widehat{y}(k)=\widehat{x}^{(0)}(k) /(1-\bar{\delta} \%)
$$

where $\bar{\delta}=\left(\delta_{1}+\delta_{2}\right) / 2, \delta_{1}, \delta_{2}$ are the lower bound and upper bound of certain state.
Once one model is established, we should test whether it is reasonable. Grey model usually test by posterior variance test method.

The mean value and variance of original data series are:

$$
\overline{\mathrm{x}}=\frac{1}{\mathrm{n}} \sum_{\mathrm{k}=1}^{\mathrm{n}} \mathrm{x}^{(0)}(\mathrm{k}) \mathrm{S}_{1}{ }^{2}=\frac{1}{\mathrm{n}} \sum_{\mathrm{k}=1}^{\mathrm{n}}\left(\mathrm{x}^{(0)}(\mathrm{k})-\overline{\mathrm{x}}\right)^{2}
$$

The residual can be defined as: $q(k)=x^{(0)}(k)-\widehat{x}^{(0)}(k)$, and the mean value and variance of all the residual of the data are:

$$
\overline{\mathrm{q}}=\frac{1}{\mathrm{n}} \sum_{\mathrm{k}=1}^{\mathrm{n}} \mathrm{q}(\mathrm{k}) \mathrm{S}_{2}{ }^{2}=\frac{1}{\mathrm{n}} \sum_{\mathrm{k}=1}^{\mathrm{n}}(\mathrm{q}(\mathrm{k})-\overline{\mathrm{q}})^{2}
$$

The GMCM can be tested using small error probability as:

$$
p=P\left\{|q(k)-\bar{q}|<0.6475 S_{1}\right\}
$$

\section{LONG-TERM PREDICTION OF EXTREME SEA CONDITION OF THE SOUTH CHINA SEA}

In this study, measured data of typhoon induced wind speed, wave height and wave period of Dapeng Bay (duration 19641989) are used to establish the AGO model. The prediction data from 1990 to 1999 using GMCM will be checked with the synchronal measured data.

Table1 lists the developing coefficient $a$ and grey input coefficient $u$ in the grey models of wind speed, wave height and wave period. In GMCM the residual error correction should be performed by using Markov chain. The revised prediction data are shown in Fig.1 to Fig.3, which are compared by measured data series. Posterior variance ratio $C$ and small error probability $p$ of different variables are also listed in Table2. Result shows that GMCM is effective and reasonable model for long-term prediction of extreme sea state factors induced by typhoon.

Table1. Parameters of GMCM

\begin{tabular}{|l|l|l|l|l|}
\hline & $\mathrm{a}$ & $\mathrm{u}$ & $\mathrm{C}$ & $\mathrm{p}$ \\
\hline Wind speed & -0.0155 & 15.43 & 0.42 & 0.89 \\
\hline Wave height & -0.0104 & 4.19 & 0.46 & 0.87 \\
\hline Wave period & 0.0006 & 8.99 & 0.31 & 0.93 \\
\hline
\end{tabular}




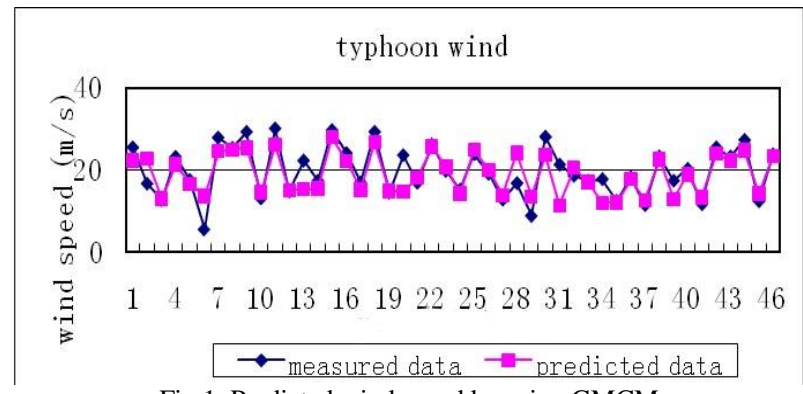

Fig.1. Predicted wind speed by using GMCM

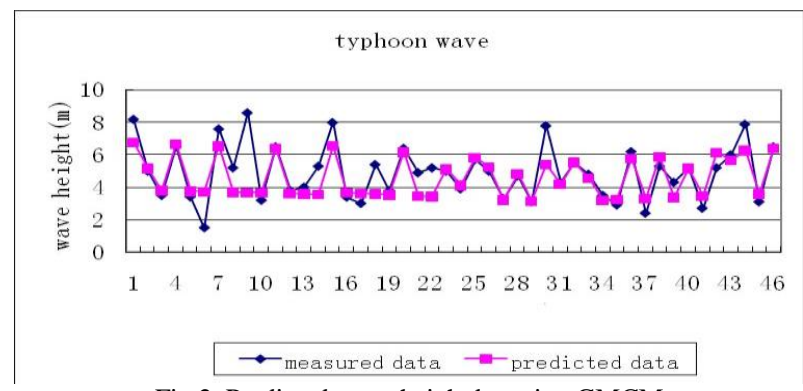

Fig.2. Predicted wave height by using GMCM

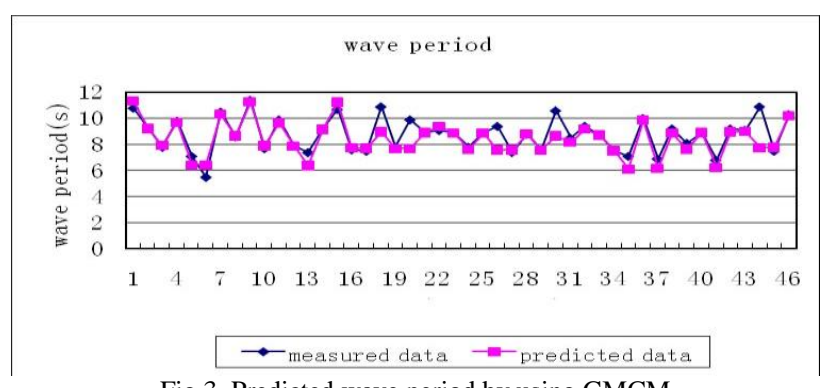

Fig.3. Predicted wave period by using GMCM

The measured and hindcast data of wind speed, wave height and wave period during 1964 to 1999 are taken as sample for long-term probability analysis. According to the diagnostic checks results, all the data of the wind speed, the wave height, and the period well fit to the generalized extreme value distribution (see Fig.4-6). The parameters of marginal distributions are shown in Table 2
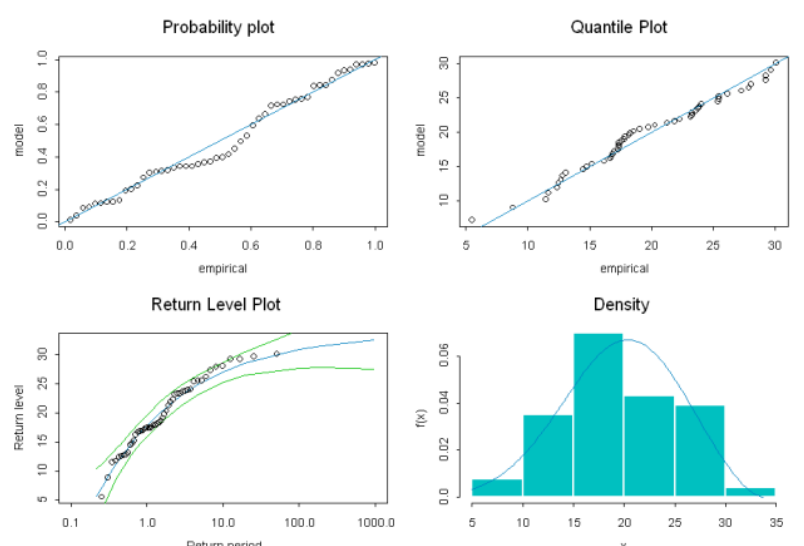

Fig. 4. Distribution of diagnostic testing of wind speed
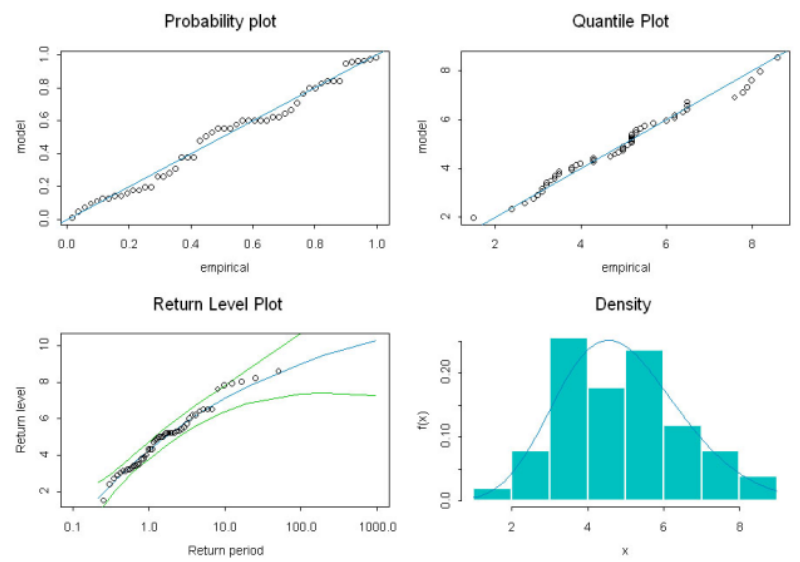

Fig.5. Distribution of diagnostic testing of wave height
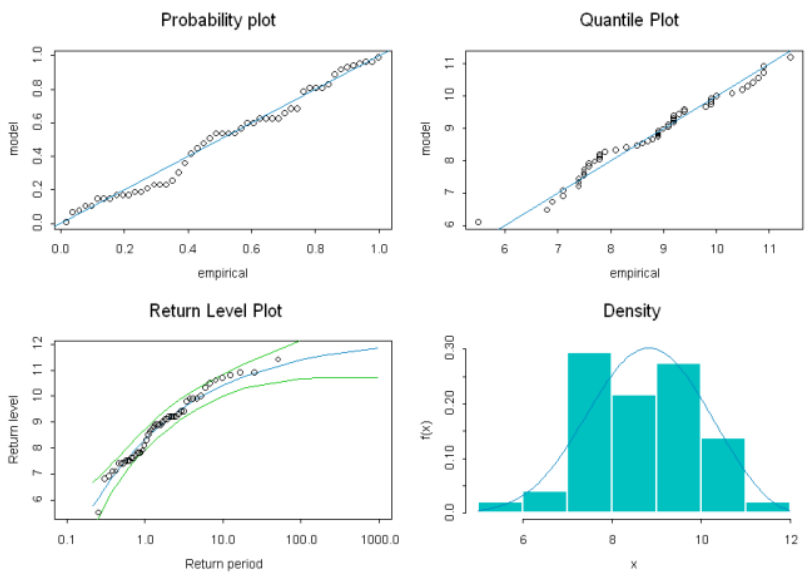

Fig. 6. Distribution of diagnostic testing of wave period

Table 2. Parameters of marginal distribution

\begin{tabular}{|c|c|c|c|}
\hline Variable & $\begin{array}{l}\text { Wave } \\
\text { height }(\mathrm{m})\end{array}$ & $\begin{array}{l}\text { Wave } \\
\text { Period(s) }\end{array}$ & $\begin{array}{l}\text { Wind } \\
\text { Speed } \\
(\mathrm{m} / \mathrm{s})\end{array}$ \\
\hline $\begin{array}{l}\text { Location } \\
\text { parameter } \mu\end{array}$ & 4.26 & 17.85 & 8.33 \\
\hline $\begin{array}{l}\text { Standard } \\
\text { deviation of } \mu\end{array}$ & 0.235 & 0.94 & 0.20 \\
\hline $\begin{array}{l}\text { Scale } \\
\text { parametero }\end{array}$ & 1.49 & 5.94 & 1.29 \\
\hline $\begin{array}{l}\text { Standard } \\
\text { deviation of } \sigma\end{array}$ & 0.17 & 0.71 & 0.147 \\
\hline $\begin{array}{l}\text { Shape } \\
\text { parameter }\end{array}$ & -0.17 & -0.37 & -0.33 \\
\hline $\begin{array}{l}\text { Standard } \\
\text { deviation of } \xi\end{array}$ & 0.11 & 0.12 & 0.105 \\
\hline
\end{tabular}

\section{CONCLUSIONS}

The wave characteristics of South China Sea have typical season variations due to the influence of typhoon system. 
GMCM is an accurate model for predictions of typhoon induced wind speed, wave height and wave period.

\section{ACKNOWLEDGMENT}

This work is supported by China Postdoctoral Science Foundation (No. 201104650) and Ocean Renewable Energy Plan (QDME2011GD02).

\section{REFERENCES}

[1] Hatada Y, Yamaguchi M, Ohfuku M, Li M.J. and Nonaka H. A System for Estimating Wave Climate and Wave Extremes Based on Long Term Wave Hindcast. Natural Disaster Science, J.JSNDS, 19-1, (2000).p.69-85.

[2] Jonathan A Tawn. Modeling multivariate extreme value distributions. Biometrika, Vol.77, No.2, (1990). P.245-253.

[3] Liu T.F. and Ma, F.S. Prediction of Extreme Wave Heights and Wind Velocities. Journal of the Waterway Port Coastal and Ocean division, ASCE,106, No.WW4, (1980). p.469-479.

[4] Liu.T.F. Long term Distribution of Hurricane Characteristics. Proc. Offshore Technology Conference OTC 4325. (1982). p.305-313.
[5] Liu D.F, Wen SQ,Wang L.P. Poison-Gumbel Mixed Compound Distribution and its application. Chinese Science Bulletin,Vol.47, No.22, (2002). P.1901-1906.

[6] Liu Defu, Pang Liang, Fu Gang, Shi Hongda. Joint Probability Analysis of Hurricane Katrina 2005. Proc Int Offsh Pol Eng Conf San Francisco, USA, Vol.3, (2006), p.74-80

[7] Liu Defu, Wang Liping, Pang Liang. Theory of multivariate compound extreme value distribution and its application to extreme sea atae prediction. Chinese Science Bulletin.Vol.51, No.23, (2006), p.2926-2930.

[8] Pang Liang, Liu Defu, Yu Yifa, et al. Improved Stochastic Simulation Technique and Its Application to the Multivariate Probability Analysis of Typhoon Disaster. Proc. Of 17th Intern. Offshore \& Polar Eng. Con. Lisbon, Portugal, ISOPE2007. Vol.3, (2007), p.1800-1805

[9] J.L. Deng. Control Problems of Grey System. System and Control Letters,No.5, (1982). P.288-294. 